\title{
CDISC SDTM Relationship to Subject Terminology
}

National Cancer Institute

\section{Source}

National Cancer Institute. CDISC SDTM Relationship to Subject Terminology. NCI

Thesaurus. Code C100130.

Terminology associated with the relationship to subject codelist of the Clinical Data Interchange Standards Consortium (CDISC) Study Data T abulation Model (SDT M). 